patients with diabetes mellitus, is not likely a risk factor for inflammation and airway remodelling.

M. Papagianni*, A. Hatziefthimiou*, G. Chachami*, K. Gourgoulianis", P-A. Molyvdas* and E. Paraskeva* *Depts of Physiology and "Respiratory Medicine, Medical School, University of Thessaly, Larissa, Greece.

\section{STATEMENT OF INTEREST}

None declared.

\section{REFERENCES}

1 Liu MC, Riese RJ, Van Grundy K, et al. Effects of inhaled human insulin on airway lining fluid composition in adults with diabetes. Eur Respir J 2008; 32: 180-188.
2 Halayko AJ, Amrani Y. Mechanisms of inflammationmediated airway smooth muscle plasticity and airway remodeling in asthma. Respir Physiol Neurobiol 2003; 137: 209-222.

3 Halayko AJ, Solway J. Plasticity in skeletal, cardiac, and smooth muscle: invited review: molecular mechanisms of phenotypic plasticity in smooth muscle cells. J Appl Physiol 2001; 90: 358-368.

4 Papagianni M, Hatziefthimiou A, Chachami G, Gourgoulianis K, Molyvdas P-A, Paraskeva E. Insulin causes a transient induction of proliferation via activation of the PI3-kinase pathway in airway smooth muscle cells. Exp Clin Endocrinol Diabetes 2007; 115: 118-123.

\title{
Palliative and end-of-life care for patients with severe COPD
}

\section{To the Editors:}

We congratulate CURTIS [1] on his excellent review on the very important and under-recognised topic of palliation in endstage chronic obstructive pulmonary disease (COPD). We agree that the use of noninvasive ventilation (NIV) as palliation may be impractical in the hospice environment, and that NIV should not be used first-line for the palliation of breathlessness in COPD. However, we do not think that there is sufficient recognition that in certain specific circumstances NIV may have a role in end-stage COPD.

First, as clearly stated, prognostication is exceedingly difficult in advanced COPD, and deciding if an exacerbation is likely to be recoverable or not is problematic. With acute exacerbations, more than half of patients with advanced COPD who have a "do-not-intubate" order, but receive NIV, live to hospital discharge [2]. Therefore, providing it is in accordance with the patient's wishes and in the context of hospital admission for acute hypercapnic respiratory failure, we would advocate a trial of NIV in patients who are deemed "not for invasive ventilation".

Secondly, despite the lack of supportive evidence from the current literature for the routine use of NIV as a palliative measure in advanced COPD, we would argue that in carefully selected patients in appropriately resourced environments with trained staff, there is no harm in a trial of NIV if there is the potential for significant symptomatic benefit [3]. Benefits of palliative NIV include: relief of breathlessness; ability to enable sleep; and "buying time" to ascertain patients' wishes. In the UK, patients with COPD may be admitted to hospitals unaccompanied and without casenotes, NIV is often started pending information on pre-morbid status. Furthermore, although it is best practice to ascertain a patient's wishes regarding treatment/resuscitation in advance, in practice this rarely occurs [1].

We agree with the importance of early discussion regarding the risks and benefits of noninvasive and invasive ventilation [1]. However, it would not be in a patient's best interests to offer a therapeutic option that is unlikely to be available. In intensive care units in the UK, patients with end-stage chronic obstructive pulmonary disease would be unlikely to be accepted for invasive ventilation. Furthermore, no clinician is obliged to provide an intervention that they do not believe is in the best interests of the patient. At least in the UK, this seldomdiscussed dilemma may be a factor inhibiting physicians from full and frank discussion of end-of-life issues.

\section{B.C. Creagh-Brown* and C. Shee}

*Adult Intensive Care Unit, Royal Brompton Hospital, London, and "Dept of Respiratory Medicine, Queen Mary's Hospital, Sidcup, UK.

\section{STATEMENT OF INTEREST}

None declared.

\section{REFERENCES}

1 Curtis JR. Palliative and end-of-life care for patients with severe COPD. Eur Respir J 2008; 32: 796-803.

2 Creagh-Brown B, Shee C. Noninvasive ventilation as ceiling of therapy in end-stage chronic obstructive pulmonary disease. Chron Respir Dis 2008; 5: 143-148. 
3 Shee CD, Green M. Non-invasive ventilation and palliation: experience in a district general hospital and a review. Palliat Med 2003; 17: 21-26.

DOI: 10.1183/09031936.00143208

\section{From the authors:}

I thank B.C. Creagh-Brown and C. Shee for their complimentary comments. Furthermore, I completely agree with the principles described in their letter regarding the use of noninvasive ventilation (NIV) in selected patients who have chosen to forego, or are not offered, endotracheal intubation and invasive mechanical ventilation. In fact, I had the privilege of co-authoring a recent statement published by the Society of Critical Care Medicine [1] regarding the use of noninvasive ventilation for patients with "do not intubate" orders that I think is entirely consistent with the comments by B.C. CreaghBrown and C. Shee. In that statement, we argued that the use of NIV for patients with acute respiratory failure can be classified into three categories. 1) NIV as life support with no preset limitations on life-sustaining treatments. 2) NIV as life support when patients and families have decided to forego endotracheal intubation. 3) NIV as a "purely palliative" measure when patients and families have chosen to forego all life support and are receiving comfort measures only.

As pointed out by B.C. Creagh-Brown and C. Shee, there is compelling evidence that some patients in our "second category" (those for whom invasive ventilation is not desired or indicated but who do want life-sustaining treatments) will benefit from NIV, especially those patients with acute respiratory failure from chronic obstructive pulmonary disease or congestive heart failure.
As for those in the "third category" (patients for whom NIV is used purely for the palliation of symptoms), I also agree with B.C. Creagh-Brown and C. Shee that highly selected patients at the end-of-life may receive some palliative benefit from NIV, provided their clinicians are experienced with NIV. This is an important area in need of further research, but one in which some indirect evidence of benefit exists [1]. However, I suspect I may differ from B.C. Creagh-Brown and C. Shee with regard to my area of greatest concern regarding NIV in this purely palliative setting. In my clinical experience, I see many more patients at the end-of-life exposed to NIV that is unlikely to provide any benefit than for whom this potentially beneficial therapy is withheld.

Perhaps B.C. Creagh-Brown, C. Shee and I agree that both of these concerns about the misapplication of nonivasive ventilation are problematic and we should work to limit them both.

\section{J.R. Curtis}

Division of Pulmonary and Critical Care, University of Washington, Seattle, WA, USA.

\section{STATEMENT OF INTEREST}

None declared.

\section{REFERENCES}

1 Curtis JR, Cook DJ, Sinuff T, et al. Noninvasive positive pressure ventilation in critical and palliative care settings: understanding the goals of therapy. Crit Care Med 2007; 35: 932-939.

\section{No effects of EPHX1 polymorphisms on the level or change of $F E V_{1}$ in the general population}

\section{To the Editors:}

CHAPPELl et al. [1] recently found that several single nucleotide polymorphisms (SNPs) in the glutamate cysteine ligase (catalytic subunit; GCLC) and epoxide hydrolase 1 (EPHX1) do not associate with the presence or severity of chronic obstructive pulmonary disease (COPD). We have previously shown in two independent population-based cohorts that the functional polymorphism rs17883901 and the trinucleotide GAG repeat in GCLC form unique genotype combinations that are associated with lower lung function in interaction with smoking [2]. Chappell et al. [1] did not study the latter variation in GCLC, nor the interaction between SNPs and smoking in relation to COPD severity, which is of special interest given the in vivo role of GCLC. They additionally studied SNPs in EPHX1, including nonsynonymous SNPs (nsSNPs) Tyr113His and His139Arg that previously provided both positive and negative associations with COPD across studies and races [1, 3-7]. We aimed to extend these findings by showing the effects of EPHX1 SNPs on the level and change of forced expiratory volume in one second (FEV1) in the general population, and additionally investigated whether EPHX1 SNPs smoking interactions are associated with both outcomes, as was the case with GCLC.

We genotyped five SNPs in EPHX1 (three SNPs tagging the $5 \mathrm{~kb}$ promoter region: rs3753658, rs10753410 and rs2854450; and two nsSNPs: rs1051740 (Tyr113His) and rs2234922 